\title{
Turning Technical Experts into Multifunctional Managers of Protected Areas
}

\section{A Master of Science (MSc) program at the University of Klagenfurt offers professional training for experts concerned with managing and planning protected areas}

\author{
Sigrun Lange \& Barbara Müller
}

\section{Abstract}

Exactly 100 years ago the first national parks in Europe were established in Sweden. Since then there has been a veritable boom of newly designated protected areas across the globe while biodiversity has decreased all the while. There are manifold reasons why the global network of protected areas obviously fails to "achieve the long-term conservation of nature with its associated ecosystem services" (IUCN 2008). The Nature Conservancy, a US environmental NGO, for example, pointed out significant weaknesses in the design and management of protected areas which leave them vulnerable to threats such as population pressures or the effects of climate change. In order to deliver on their promise of a sustainable future, protected areas need to be well-funded, well-managed and have the support of both governments and society. This calls for professional staff. Frequently both natural and social scientists lack adequate training to deal successfully with the challenging tasks that come with managing a protected area.

Nowadays this knowledge gap can be filled by special master courses on the "Management of Protected Areas". One of them was launched in 2005 at the University of Klagenfurt, Austria. The course has become an internationally well-established hub for training integrated management of protected areas. The application deadline for the new course is 30th of June 2009. It will start in September 2009 and run till June 2011.

\section{Protected areas and the preservation of biodiversity}

Protected areas are essential for biodiversity conservation: they are key elements of national and international conservation strategies, set aside to act as refuges for species and to maintain ecological processes. Yellowstone, the world's first national park, was established in 1872. Since then the number and acreage of protected areas have risen dramatically (see Figure 1). In the last 40 years the global network has increased from an area the size of the United Kingdom to an area the size of South America. These figures seem quite impressive but significant challenges remain. Many protected areas have been set up in remote unpopulated regions where no resistance was to be expected (e.g. mountains or ice-fields), others were designated but not fully implemented or managed (IUCN 2008). Therefore, despite the fact that $12 \%$ of the world's land surface is officially protected, it is unlikely that it will be possible to reduce the current rate of biodiversity loss by 2010 as demanded by the parties to the Convention of Biological Diversity tected Areas (WDPA)
(CBD, 2010-target, BfN 2007). In a new approach, key biodiversity areas are being identified by criteria of vulnerability and irreplaceability (Langhammer et al. 2007).

\section{Good management practices - a challenge}

In recent decades there has been a paradigm shift in the role of protected areas from strictly conserved reserves without regard to the impact on local people (top-down approach) to a broader conceptual and practical approach including areas of sustainable use and participation processes (bottom-up approach)

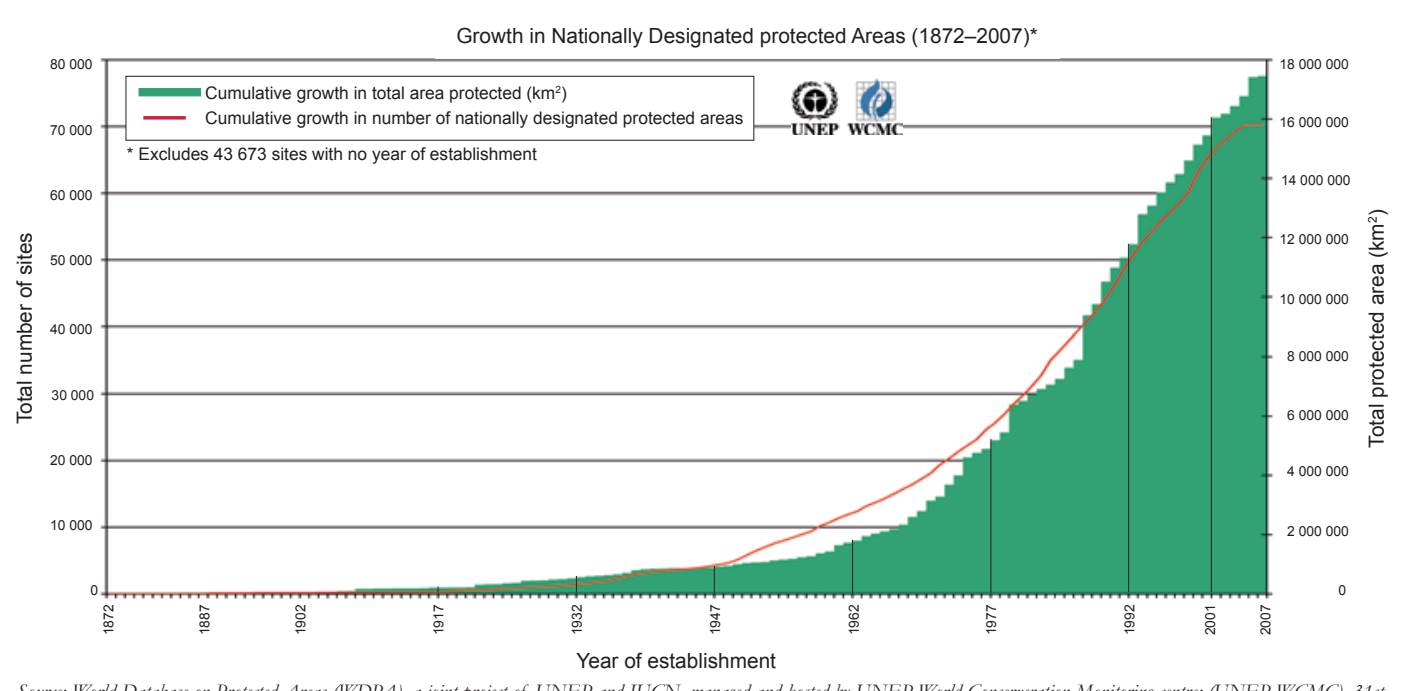

Source: World Database on Protected Areas (WDPA), a joint project of UNEP and IUCN, managed and hosted by UNEP-World Conserveration Monitoring centre; (UNEP-WCMC), 31st January 2008.Please contact protectedareas@unep-womc.org for more information

Figure 1 - Growth in number and acreage of national protected areas since 1872, from the World Database on Pro- 
(Phillips 2003). Planning and management of protected areas thus becomes an even more challenging and dynamic task. Managers can no longer be content just to preserve plants and animals. Instead they need to involve various stakeholders and motivate them to contribute to a sustainable use of the natural resources. At the same time they have to be experts in conservation, regional development, communication, negotiation, conflict resolution, marketing, finance, economics and management. Often natural or social scientists with regular university degrees are overwhelmed by such responsibilities. There clearly is a lack of the necessary inter- and transdisciplinary training. Efficient management of today's protected areas calls for new forms of professional training.

\section{Turning experts into multifunctional managers}

In 2001, three Spanish universities (Autonomous University of Madrid, University Complutense of Madrid and University of Alcalá), in cooperation with Europarc Spain and the Foundation Fernando González Bernáldez, started offering a one year master course on protected areas management. The courses are held in Spanish and run every week from Thursday evening till Saturday (in two blocks from January till June and from September till December). The participants are mainly from Spain or Latin America (more information on http://www.uam.es/otros/fungobe/master. htm).

In 2005 another educational MSc program on the "Management of Protected Areas", developed by Michael Jungmeier (biologist and CEO of E.C.O. Institute for Ecology) and Michael Getzner (professor of economics), was launched at the University of

$\operatorname{lnfobox}$

\section{Aims of the MSc program at a glance:}

Educational objectives:

- Theoretical fundamentals: comprehensive understanding of the aims and functions of protected areas in relation to the conservation of biodiversity and integrated regional development

- Practical insights: knowledge of existing management tools and how to apply them

- Personal skills: ability to analyse and solve problems encountered in planning, establishing and managing protected areas; ability to conduct interdisciplinary dialogues with stakeholders and to develop and implement appropriate integrated solutions

Thematic focus:

- European and international categories of protected areas

- Nature conservation strategies in Central and Eastern Europe

- Integrating socio-cultural, economic and ecological aspects of protected area management

- Participative management approaches

- Applying innovative technologies and approaches

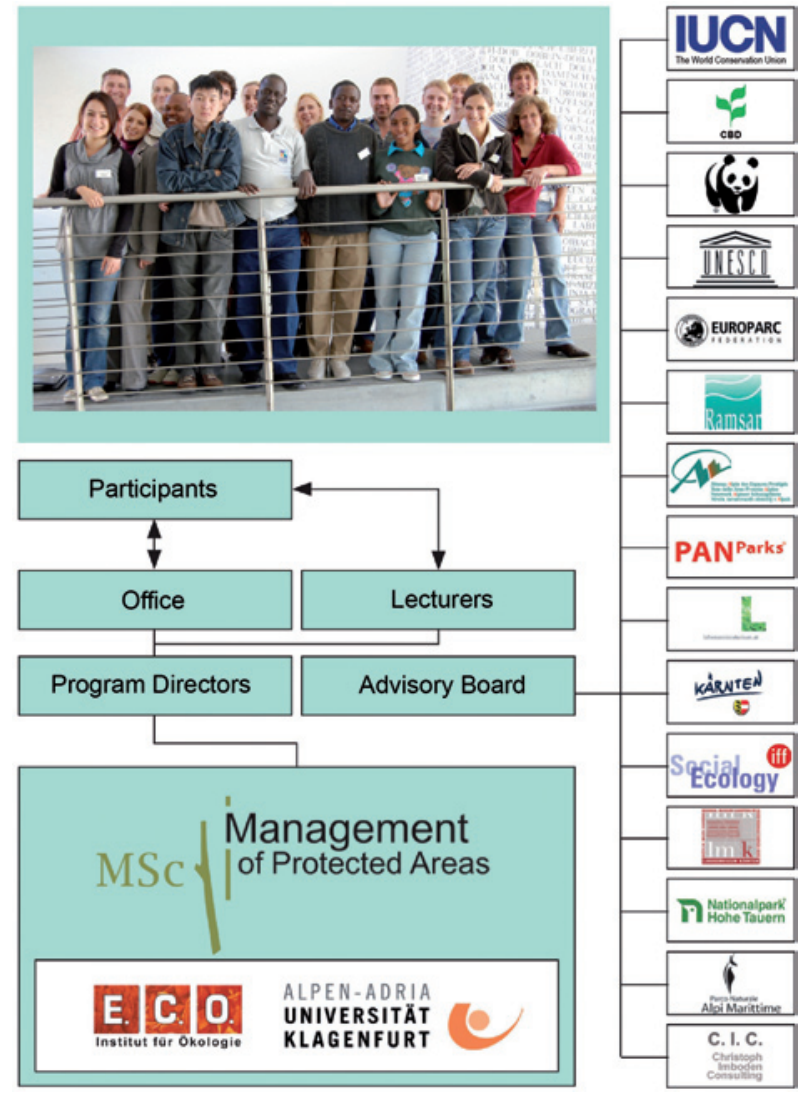

Figure 2 - Organizational structure of the MSc course at the University of Klagenfurt.

Klagenfurt in Austria. The course is integrated into the economics department - a setup that facilitates the transfer of existing business and management knowledge to the participants of the course.

Organizations like the IUCN, UNESCO, EUROPARC, ALPARC, WWF, PAN Parks and secretaries of relevant international conventions (e.g. Convention on Biological Diversity and the Ramsar Convention on Wetlands) as well as numerous individual experts have contributed to the structure and content of the curriculum. These days they continue to support and shape the program as members of the advisory board or as one of about 40 lecturers from different disciplines and countries (see Figure 2).

„This course is an outstanding and innovative educational opportunity. Not only does it provide important training but also a professional momentum for nature conservation in Europe", Michael Succow emphasizes. The former professor at the German University of Greifswald and Alternative Nobel Prize winner in 1997 (see Figure 3) is one of the seventeen members of the advisory board who accompany and support the program and share their knowledge with the participants (Figure 4).

\section{Curriculum and course structure}

The curriculum covers every aspect of planning and integrated management of protected areas - theoretical fundamentals, practical tools and personal skills 
(see Infobox on the left). The course is organized in nine modules held in blocks of up to ten days (altogether around 70 days of course attendance, either as classes or excursions). The classes take place at the University of Klagenfurt and in selected European protected areas. In order to qualify for admission, potential students need to hold a university degree, have a good knowledge of English and demonstrate interest in the topic. To complete the program successfully the participants have to prepare assignments for each topic covered and a master thesis of up to 60 pages. At the end of the course the successful participants are awarded a Master of Science degree.

\section{The enriching diversity of participants}

"To enable a sustainable coexistence of protection and use is a complex task. It requires competences in ecological, economic and socio-cultural subjects and good communication skills. With this course we want to address ambitious personalities with different professional backgrounds from Central, Southern and Eastern Europe", says Michael Getzner, scientific director of the program. However, the first two classes also attracted interest from participants of other countries like Belarus, Nepal, Tibet, Kenya, Tanzania and Uganda. The diversity of the students' professions, experiences and cultural backgrounds introduces new learning experiences and methods of problem sol ving and eventually leads to a broader horizon and to friendships with people from all over the world (Figure 5). In the second course, experts of nature conservation agencies shared their knowledge and experiences with colleagues working in protected areas, financial institutions, tourism or as language trainers. This interdisciplinary collaboration helped the participants to cope even with difficult tasks (Figure 6).

\section{Quality, innovation and entrepreneurship}

The first participants of the program successfully finished in June 2007. They presented the results of their master thesis to an international audience of protected area managers, scientists and representatives of NGOs in the course of the „Klagenfurt Days of Protected Areas" which serve as a platform for sharing new ideas. The public was "impressed" by the quality and innovative approaches of the theses, which ranged from the natural sciences to business administration and economics. This event will again take place in June 2009. The quality and practical applicability of the training have already been confirmed on the job market. The majority of the first student generation has successfully applied for positions in consulting or managing positions or started their own ventures.

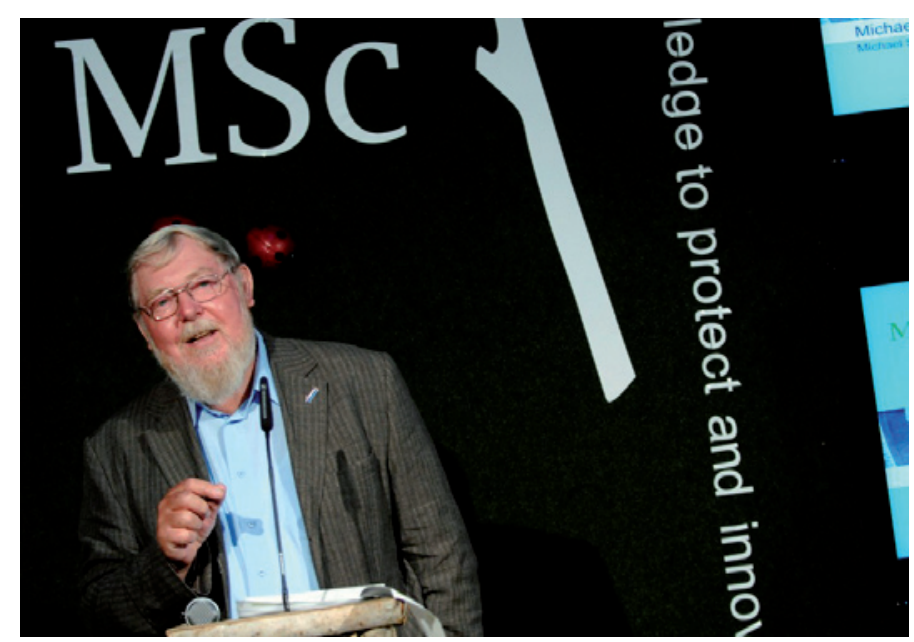

Figure 3 - Michael Succow, winner of the Alternative Nobel Prize, accompanies the MSc Program as one of 17 members of the advisory board. (C) Bauer

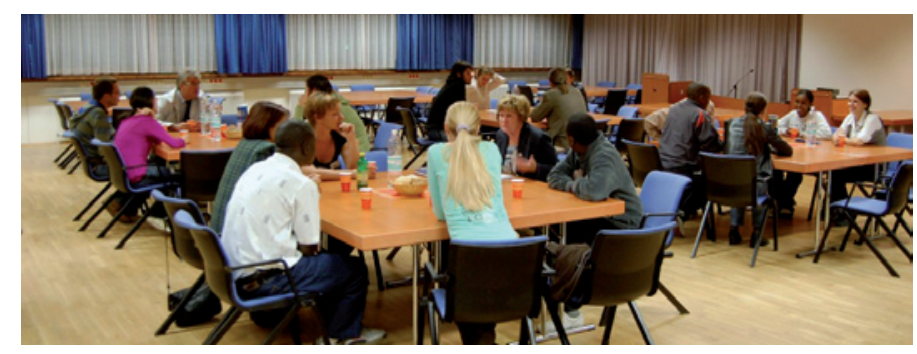

Figure 4 - The participants of the MSc Program get to know members of the advisory board. (C) Jungmeier

\section{MSc network expands}

While the second generation of students is at present working on their master theses, the preparation for the third run of the program has already started. "With this MSc course we have developed a unique combi-

\section{$\operatorname{lnfobox}$}

\section{Administrative details of the MSc Program:}

Course language: English

Minimum requirements for admission: university degree or equivalent qualification, good working knowledge of English and interest in the topic

Tuition fee: EUR 12400 (plus travel expenses and living costs during the modules) Structure: 9 modules in blocked courses (altogether around 70 days)

Duration: September 2009 to June 2011

Location: University of Klagenfurt (Austria) and selected protected areas in Central, Southern and Eastern Europe

Application deadline: 30/06/2009

Homepage: www.mpa.uni-klu.ac.at

Contact (program directors):

- Prof. Dr. Michael Getzner:

michael.getzner@uni-klu.ac.at

- Mag. Michael Jungmeier:

jungmeier@e-c-o.at

Address: MSc Programme "Management of Protected Areas", c/o Department of Economics, University of Klagenfurt, Universitätsstraße 65-67, 9020 Klagenfurt, Austria 


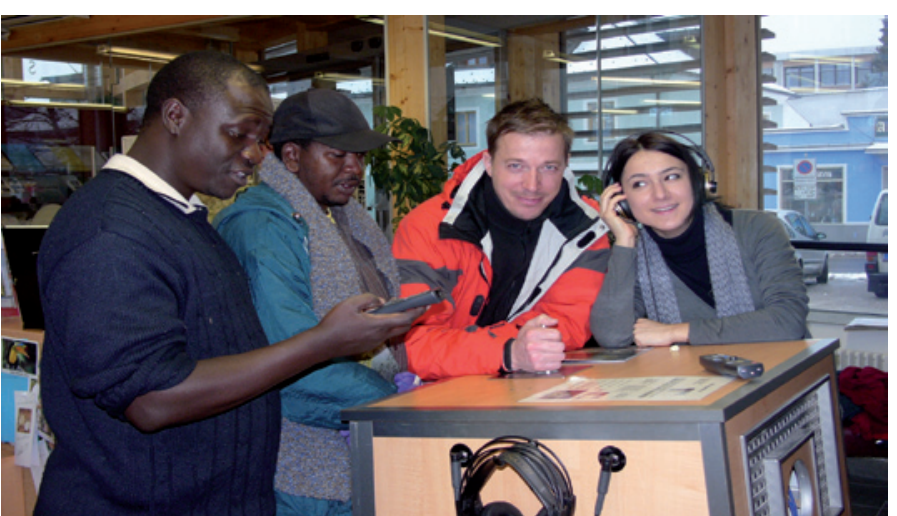

Figure 5 - While sharing experiences, participants from all over Europe and three East African countries became friends in the second MSc course. (C) Lange

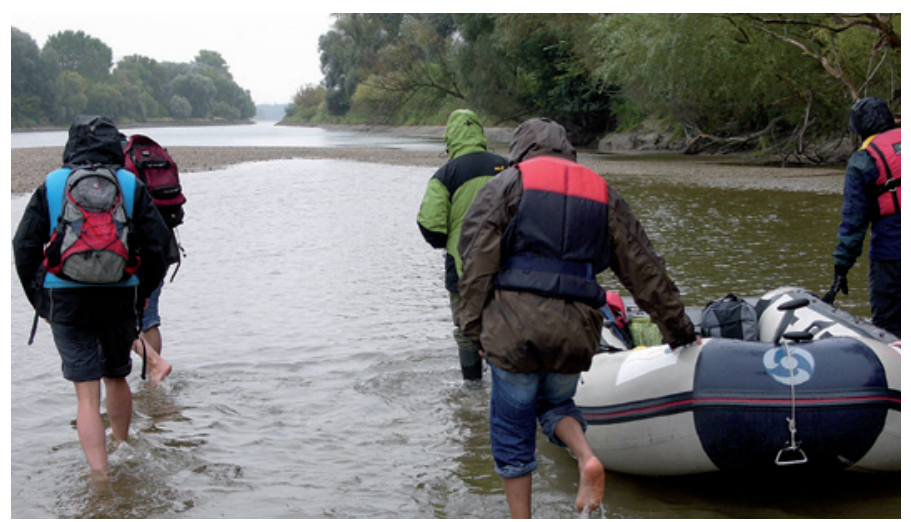

Figure 6 - Excursion in the Donanauen National Park (AT): managing protected areas often is a tough job - a thick skin is needed to cope with the associated tasks. (C) Lange

nation of knowledge and skills for the management of protected areas. This is the nucleus of a network which will expand," Michael Jungmeier, codirector of the program, explained. He is engaged in linking related training programs like the one at the University of Madrid. Together with the Spanish colleagues, he and Michael Getzner have contributed significantly to setting up the EUROPARC Working Group on Academic Education on Protected Areas.

In addition former students are building an internal network by setting up an alumni club which shall serve as a platform for all people involved in the course to share experiences and knowledge in the longer term. Ongoing discussions, problem-solving and excursions allow for lively knowledge transfer and strengthen contacts even after graduation.

For anyone interested in the program that starts in September 2009, the main points are outlined in the infobox on the previous page.

\section{References}

Bundesamt für Naturschutz, BfN (ed) 2007. Die Lage der biologischen Vielfalt. 2. Globaler Ausblick. Naturschutz und Biologische Vielfalt 4.

Convention on Biological Diversity, Information on 2010-target. Available at: http:/ /www.cbd.int/2010-target/
Dudley, N. (ed.) 2008. Guidelines for Applying Protected Area Management Categories. Published by IUCN.

Langhammer, P.F. et al. (eds.) 2007. Identification and Gap Analysis of Key Biodiversity Areas. Targets for Comprehensive Protected Area Systems. World Commission on Protected Areas, Best Practice Protected Area Guidelines Series 15, Gland.

Phillips, A. 2003. Turning Ideas on Their Head - The New Paradigm for Protected Areas. The George Wright FORUM. 20, 2: 1-25.

The Nature Conservancy (ed.) 2009. Parks under pressure. Threats to protected areas. Available at: http:// www.nature.org/initiatives/protectedareas/issues/ (accessed: 06/01/09)

\section{Authors}

\section{Sigrun Lange}

is about to graduate in the Master of Science Program. Her master thesis focuses on cross-border cooperation in protected area management. She is an expert on planning and implementing the UNESCO concept of biosphere reserves. As CEO of E.C.O. Germany $\mathrm{GmbH}$ she offers consulting services for planning and managing protected areas.

Lange@e-c-o-deutschland.de

www.e-c-o-deutschland.de

\section{Barbara Ursula Müller}

is a graduate from the first run of the Master of Science program. In her thesis she focused on the funding opportunities presented by corporate sponsorships for protected areas in the alpine region. She has a business background in corporate finance and investment banking. She is part of the Earthmind network of consultants dedicated to sustainability and offers consulting services on managing and financing protected areas.

bmueller@earthmind.net

http://earthmind.net/mueller.htm 